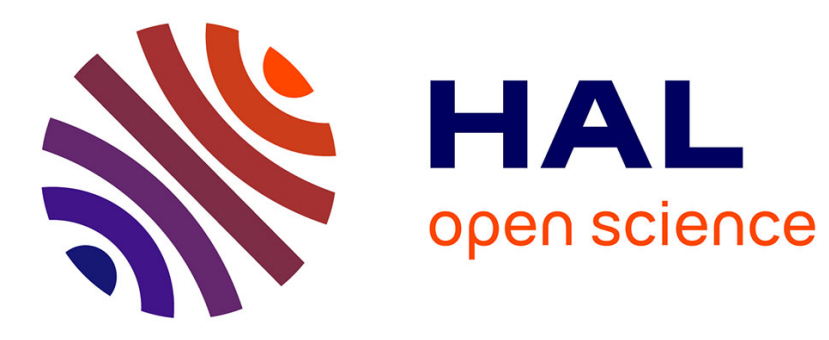

\title{
Steering polymer growth by molding nanochannels: 1,5-hexadiene polymerization in high silica mordenite
} Marco Fabbiani, Giorgia Confalonieri, Sara Morandi, Rossella Arletti, Simona

Quartieri, Mario Santoro, Francesco Di Renzo, Julien Haines, Riccardo Fantini, Gloria Tabacchi, et al.

\section{To cite this version:}

Marco Fabbiani, Giorgia Confalonieri, Sara Morandi, Rossella Arletti, Simona Quartieri, et al.. Steering polymer growth by molding nanochannels: 1,5-hexadiene polymerization in high silica mordenite. Microporous and Mesoporous Materials, 2021, 311, pp.110728. 10.1016/j.micromeso.2020.110728 . hal-03002032

\section{HAL Id: hal-03002032 https://hal.science/hal-03002032}

Submitted on 25 Nov 2020

HAL is a multi-disciplinary open access archive for the deposit and dissemination of scientific research documents, whether they are published or not. The documents may come from teaching and research institutions in France or abroad, or from public or private research centers.
L'archive ouverte pluridisciplinaire HAL, est destinée au dépôt et à la diffusion de documents scientifiques de niveau recherche, publiés ou non, émanant des établissements d'enseignement et de recherche français ou étrangers, des laboratoires publics ou privés. 


\title{
Steering polymer growth by molding nanochannels: 1,5-hexadiene polymerization in high silica mordenite
}

\author{
Marco Fabbiani a,b, Giorgia Confalonieri c, Sara Morandi a,b, Rossella Arletti c, *, Simona \\ Quartieri c, Mario Santoro d, Francesco Di Renzo e, Julien Haines e, Riccardo Fantini c, Gloria \\ Tabacchi f, **, Ettore Fois f, Giovanna Vezzalini c, Gabriele Ricchiardi a,b, Gianmario Martra \\ $\mathrm{a}, \mathrm{b}$ \\ a Department of Chemistry, University of Torino, Via Pietro Giuria 7, 10125, Torino, Italy \\ b Interdepartmental Centre "Nanostructured Interfaces and Surfaces" - NIS, University of Torino, Via Pietro \\ Giuria 7, 10125, Torino, Italy \\ c Department of Chemical and Geological Sciences, University of Modena e Reggio Emilia, Via Campi 103, 41125, \\ Modena, Italy \\ d National Institute of Optics CNR-INO and European Laboratory for Non Linear Spectroscopy LENS, Via Nello \\ Carrara 1, 50019, Sesto Fiorentino, Italy \\ e ICGM, University of Montpellier, CNRS, ENSCM, Place Eug'ene Bataillon, 34095, Montpellier, France \\ f Department of Science and High Technology and INSTM, University of Insubria, Via Valleggio 9, 22100, Como, \\ Italy
}

Keywords: Zeolite Polymerization Nanostructure Density functional calculation X-ray diffraction

\section{A B S T R A C T}

Zeolites are known as scaffolds for the assembly of molecules via non-covalent interactions yielding organized supramolecular materials. Yet their potential in driving the growth of lowdimensional systems requiring covalent bond formation is still unexplored. We incorporated 1,5hexadiene in the channels of a high-silica mordenite and analyzed the material by infrared spectroscopy, X-ray powder diffraction, thermogravimetry and modeling techniques. Due to the few zeolite acid sites, 1,5-hexadiene experiences a slow conversion to a polymer mainly formed by cyclopentane units and featuring short side chains that are able to fit the channels. The shapedirecting abilities of zeolite frameworks play a two-fold role, involving first the organization of the monomers inside the void-space and then the linear growth of the chain dictated by the channel geometry. These findings highlight the molding action of zeolites in directing transformations of covalent bonds under ambient conditions and may provide insights for obtaining confined polymers with intriguing prospective applications.

1. Introduction The preparation and exploitation of low-dimensional materials is a fundamental issue in nanoscience and nanotechnology. Microporous materials such as zeolites are of great interest in this context, because of their unique pore topologies [1-3]. The "open space" of zeolites can be filled by suitable encapsulated guest molecules and cations that can diffuse through the pores and form organized low-dimensional aggregates tailored by the zeolite channels [4-7]. Moreover, the fine tuning of their pore architecture and of their hydrophilic/hydrophobic character can improve their performance for technological or industrial applications [8-18]. Different kinds of reactions can be promoted and accomplished in zeolite pores. For example, the formation of mixtures of long-chain polymers and small oligomers of 
pyrrole and thiophene have been reported to occur inside transition-metal substituted zeolites, such as $\mathrm{Cu}$ - or Ni-mordenites [19,20]. Also, the presence of Brønsted acid sites [21-25] may strongly affect the formation of a polymer inside the zeolite cavities: in particular, acidic zeolites themselves can induce a polymerization reaction [26]. The preparation - via a chemical reaction of a continuous organic conductive nanowire embedded in zeolite micropores would therefore be of fundamental relevance in advanced materials fabrication. In fact, preparing isolated, selfstanding, densely packed conducting polymers is extremely challenging when conventional protocols are adopted, since the aggregation and bending of chains prevent the production of real 1D systems [26]. Conversely, by imposing pressure (a few GPa) on zeolite systems, it is possible to induce a rearrangement of the chemical bonds among guest species by simple mechanical tuning of the intermolecular/interatomic distances [27]. Following this procedure, linear chains of polyethylene [28], polyacetylene [29] and polycarbonyl [30] can be synthesized inside zeolite channels and, very recently, phenylacetylene has been oligomerized at high pressure inside the zeolite Mordenite [31]. The aim of our study, which is a part of a wider project aimed at the preparation of conductive polymers embedded in a protective matrix, is to exploit the template effectiveness of zeolite in inducing a polymerization along preferential directions that would not occur in bulk. This paper is the first step towards the preparation of a hybrid material made from a linear polymer identified as suitable for pyrolysis to obtain a conductive polymer protected inside a hydrophobic matrix. The resulting innovative material would have the potential to be exploited in several technological applications including, for example, gas sensing. In this field, in fact, the ability to fully exploit the properties of such a hybrid (i.e. its hydrophobicity, huge surface area and confinement of the host species) would yield the combined advantages of low cross-sensitivity to humidity and high sensitivity. In addition, an effective host-guest interaction is expected to increase the stability of the guest material. Clearly, these are all desirable characteristics for a gas sensor but, despite several years of investigation using different approaches, their development is yet to be fulfilled. As a zeolite scaffold, we chose a high silica mordenite $(H S-M O R)$ (Fig. 1a), while as the molecule to polymerize we selected 1,5-hexadiene (hexa) (Fig. 1b). HS-MOR was selected for the following reasons: i) the framework must have a unidimensional channel system to promote the synthesis of isolated 1D polymer chains; ii) the dimensions of the pores must allow the penetration of hexa; iii) a residual porosity should be maintained after polymerization to allow the gas transit for exploitation in gas sensing. The unidimensional system of parallel channels in MOR (see the section "Materials" for a detailed description of the structure) perfectly fits with these requirements since hexa can enter (andconsequently may be polymerized) in the $12 \mathrm{MR}$ channels and the gas to be sensed can circulate in the smaller channels $(8 \mathrm{MR})$ and be in contact with the conductive wire through side pockets. Hexa was chosen since its polymerization can result in an almost linear chain and the basic idea is to make the chain conductive after a selective pyrolysis reaction (not treated here). It is worth noting that, in the absence of confinement, this molecule undergoes a series of complex reactions (e.g. Cope rearrangement [32], dimerization [33], polymerization [34]) characterized by intricate paths, leading to a mixture of products. A regular polymer, using 1, 5hexadiene as a monomer, can be obtained only via a homogeneous Ziegler-Natta catalyst, leading to poly (methylene-1,3-cyclopentane) (PMCP) [34]. 


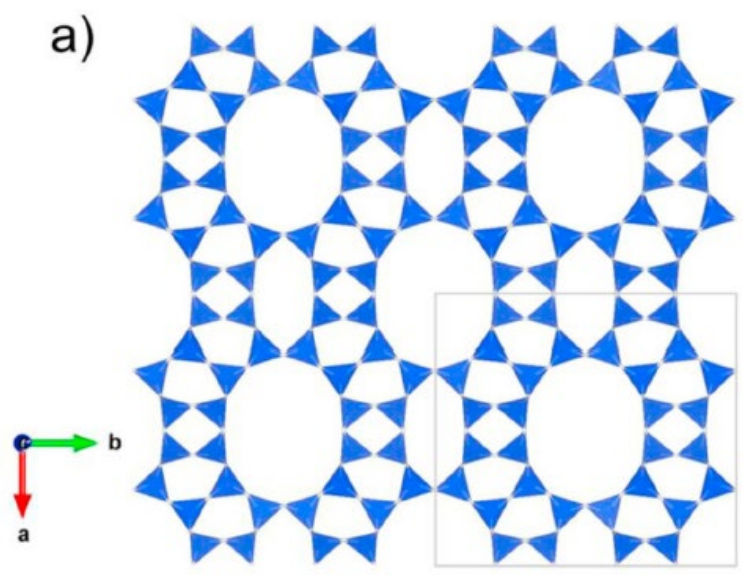

b)

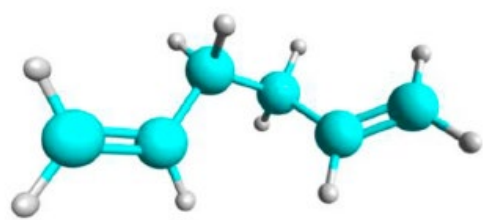

Fig. 1. a) $H S-M O R$ framework structure viewed along the [001] direction (the unit cell is drawn as grey solid lines); b) ball-and-stick representation of 1,5- hexadiene. The length and the maximum diameter of the 1,5-hexadiene molecule (inclusive of van der Waals radii) are $9.5 \AA$ and $5.0 \AA$, respectively. Color code: $\mathrm{C}=$ cyan; $\mathrm{H}=$ white. (For interpretation of the references to color in this figure legend, the reader is referred to the Web version of this article.)

\section{Experimental}

2.1. Materials High-silica mordenite (HS-MOR, $\mathrm{SiO} 2 / \mathrm{A} 12 \mathrm{O} 3$ ratio $\sim 200 ; \mathrm{Na} 2 \mathrm{O}<0.1 \mathrm{wt} \%$ ) was purchased from the Tosoh Corporation (Japan) in its protonated form (code HSZ-690HOA). The crystal structure of mordenite [35] (framework type MOR [36]) is built up from an assembly of single 6-membered rings (6 MR) forming sheets linked by single 4-membered rings (4 MR) or

else from a combination of 5-1 secondary building units. As shown in Fig. 1a, MOR exhibits a 1D channel system resulting from two types of channels both running parallel to the $c$ axis: large 12 MR channels ("free diameters" $6.5 \times 7.0 \AA$ ) and strongly elliptic 8-membered rings $(8 \mathrm{MR})$ channels ('free diameters"' $2.6 \times 5.7 \AA$ ). These channels are interconnected along the [010] direction through side pockets delimited by $8 \mathrm{MRs}$ ' that, in turn, form a sinusoidal channel ('free diameters"' $3.4 \times 4.8 \AA$ ) running parallel to the $b$ axis. Only the main $12 \mathrm{MR}$ channels are accessible to hydrocarbon molecules. Mordenite has an orthorhombic unit cell with topological symmetry $\mathrm{Cmcm}$. The real symmetry is reduced to $\mathrm{Cmc} 21$ [37], thus avoiding a straight bond between tetrahedral TO4 units $(\mathrm{T}-\mathrm{O}-\mathrm{T}$ angle, $\mathrm{T}=\mathrm{Si}, \mathrm{Al})$, but the crystal structure remains strongly pseudo-centrosymmetric. The $H S-M O R$ used has been fully characterized and previously used in many studies [31,37-40]. Structural data and relevant details on the pristine HS-MOR used here are reported in Table 1; 1,5-hexadiene (C6H10) was purchased from SigmaAldrich (97\% purity).

2.2. High-silica mordenite loading The loading of 1,5-hexadiene was performed on a previously outgassed $H S-M O R$ at room temperature (r.t.) for $1 \mathrm{~h}$, in order to remove physisorbed water, by contacting the zeolite powder with 50 mbar of 1,5-hexadiene vapor for an increasing amount of time up to one week at r.t. followed by in situ IR spectroscopy. Samples were then outgassed (1 h, r.t.) and exposed to air before thermogravimetric and X-ray Powder Diffraction (XRPD) measurements. The loaded samples are labelled $H S-M O R$ hexa.

2.3. Thermogravimetric analysis TG analyses of pure $H S-M O R$ and of $H S-M O R$ hexa were carried out using an SDT Q600 thermal analyzer from TA Instruments by initially fluxing the sample under nitrogen for $60 \mathrm{~min}$ at $50{ }^{\circ} \mathrm{C}$ in the sample chamber to remove environmental 
Table 1

Structural parameters of HS-MOR and HS-MOR hexa and refinement parameters of HS-MOR hexa.

\begin{tabular}{|c|c|c|}
\hline \multirow[t]{2}{*}{ Space group } & \multirow{2}{*}{$\frac{\mathrm{HS}_{\mathrm{MOR}}^{\mathrm{x}}}{\mathrm{Cmcm}}$} & \multirow{2}{*}{$\frac{\text { HS-MOR hexa }}{\text { Cmcm }}$} \\
\hline & & \\
\hline a $(\AA)$ & $18.0519(8)$ & $18.0563(4)$ \\
\hline $\mathrm{b}(\AA)$ & $20.2061(8)$ & $20.2346(4)$ \\
\hline c $(\AA)$ & $7.4506(3)$ & $7.4524(1)$ \\
\hline $\mathrm{V}\left(\AA^{3}\right)$ & $2717.7(2)$ & $2722.82(7)$ \\
\hline $\mathrm{H}_{2} \mathrm{O}$ molecules p.u.c. from refinement & 3.6 & 3.5 \\
\hline $\mathrm{R}_{\mathrm{wp}}(\%)$ & & 5.32 \\
\hline $\operatorname{Rp}(\%)$ & & 3.05 \\
\hline $\mathrm{RP}^{2}(\%)$ & & 11.75 \\
\hline $\mathrm{N}_{\text {obs }}$ & & 854 \\
\hline $\mathrm{N}_{\mathrm{var}}$ & & 71 \\
\hline
\end{tabular}

${ }^{a}$ From Ref. [40].

${ }^{b}$ This work.
Table 1 Structural parameters of $H S-M O R$ and $H S-M O R$ hexa and refinement parameters of $H S$-MOR hexa. Space group HS-MORa HS-MOR hexab Cmcm Cmcm a $(\AA) 18.0519$ (8) 18.0563 (4) b (A) 20.2061 (8) 20.2346 (4)

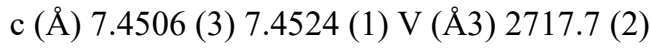
2722.82 (7) $\mathrm{H} 2 \mathrm{O}$ molecules p.u.c. from refinement 3.6 3.5 Rwp (\%) 5.32 Rp (\%) 3.05 RF2 (\%) 11.75 Nobs 854 Nvar 71 a From Ref. [40]. b This work.

fluctuations, then by increasing the temperature from 50 up to $800 \circ \mathrm{C}$ with a ramp of $10 \circ \mathrm{C} / \mathrm{min}$ under synthetic air flow.

2.4. IR experiments Absorption IR spectra were collected at r.t. with a Perkin-Elmer FT-IR System 2000 spectrophotometer equipped with an MCT detector, working in the $7200-580 \mathrm{~cm} \square$ 1 wavenumber range with a resolution of $2 \mathrm{~cm} \square 1$ (number of scans 64). For IR analysis the powder of $H S-M O R$ was compressed in self-supporting discs, with an optical thickness of about $10 \mathrm{mg} \mathrm{cm} \square 2$, placed in a home-made quartz IR cell equipped with $\mathrm{KBr}$ windows and connected to a glass vacuum line (residual pressure: $1 \times 10 \square 4$ mbar), allowing in situ adsorption and desorption experiments to be carried out. The spectrum of 1,5-hexadiene in the vapor phase was collected by introducing the vapors of the molecule at $\mathrm{p}=25 \mathrm{mbar}$ in a cell for gas measurements, with an optical path of $10 \mathrm{~cm}$.

2.5. XRPD experiments An X-ray powder diffraction experiment was performed at ID15b beamline of ESRF (Grenoble) on the 1,5-hexadiene-loaded samples (HS-MOR hexa). The powder was placed in a $0.3 \mathrm{~mm}$ quartz capillary mounted on a spinning goniometer head. The diffraction data $(\lambda=0.412015 \AA)$ were collected in Debye-Scherrer geometry on a MAR555 detector with a sample-detector distance of $547.5 \mathrm{~mm}$. A one-dimensional diffraction pattern was obtained by integrating the two-dimensional images with the program Dioptas [41]. A preliminary data collection of $H S-M O R$ hexa was performed at ID22 beamline at ESRF. Rietveld profile fitting was performed in the $\mathrm{Cmcm}$ space group using the GSAS package [42] with the EXPGUI [43] interface, starting from the framework atomic coordinates reported in [31]. The extra-framework sites (water and organic moieties) were localized from the Fourier difference density map. The background curve was fitted using a Chebyshev polynomial with 28 coefficients. The pseudo-Voigt profile function proposed by Thompson and coauthors [44] was used with a peak intensity cut-off set to $0.1 \%$ of the strongest peak. Soft-restraints were applied to the T-O distances $(1.60 \AA)$ and C-C distances $(1.5 \AA)$, their weight was set at 1000 . The isotropic displacement parameters were constrained in the following way: a value for all the tetrahedral cations ( $\mathrm{Si}$ ), a second value for all the framework oxygen atoms, a third value for the carbon atoms and a fourth one for $\mathrm{H} 2 \mathrm{O}$ molecules. Refinement parameters, R-factors, adopted space group, obtained unit cell parameters on HS-MOR hexa, are listed at the right-hand side of Table 1. The final observed and calculated powder patterns of HS-MOR hexa are provided in the Supporting Information in Fig. 1S; a summary of parameters relative to the sample, the X-ray 
diffraction data collection and structure refinement are reported in Table 1S. Atomic coordinates, occupancy factors, thermal parameters and selected bond distances are reported in Tables $2 \mathrm{~S}$ and $3 \mathrm{~S}$, respectively.

2.6. Theoretical calculations The computational models for HS-MOR hexa contain two MOR crystallographic unit cells along the $c$ direction with the following stoichiometry per simulation cell (p.s.c.) [Si960192]. This framework was filled with the following models of 1,5-hexadiene based polymers (depicted in Fig. 2), labelled as A, B, C, D, E and with a stoichiometry p.s. c. of $\mathrm{C} 12 \mathrm{H} 24, \mathrm{C} 18 \mathrm{H} 36, \mathrm{C} 18 \mathrm{H} 30, \mathrm{C} 18 \mathrm{H} 32$, and $\mathrm{C} 18 \mathrm{H} 30$, respectively:



- model A: a simple alkyl chain (of the poly (methylene) type), with no side moieties - model B: a polymer with propyl group penetrating in the side pockets of MOR - model C: a regular poly (methylene-1,3 cyclopentane) polymer - model D: a chain containing cyclopentane units and lateral ethyl groups

- model E: a chain containing cyclopentane units and side vinyl groups.

Fig. 2. Graphical representation of the model 1-Dpolymers A-E. Color codes: $\mathrm{C}=$ cyan; $\mathrm{H}=$ white. (For interpretation of the references to color in this figure legend, the reader is referred to the Web version of this article.)

Because polymer chains hosted in adjacent channels are nearly isolated from each other (see Supporting Information), only one channel of the framework p.s.c. was filled with polymer models. All systems were simulated by Density-Functional-Theory (DFT). Although DFT undoubtedly has limitations due to self-interactions $[45,46]$ this modeling method delivers an acceptable standard of accuracy at a viable cost, as evidenced by benchmark calculations [4750], and successfully reproduces the framework structure of LTL [51,52], high-silica ferrierite $[15,53,54]$, and chabazite [55] obtained from in situ diffraction experiments. Such protocol ensures an adequate description of the physico-chemical properties of organic-inorganic materials [56-65]. The size of the computational cell was so large that only gamma-point calculations could be performed. Prior to geometry optimization, all models were annealed by ab initio molecular dynamics (AIMD) (see Supporting Information).

\section{Results and discussion}

3.1. IR spectroscopy The loading of 1,5-hexadiene in HS-MOR was monitored by in situ IR spectroscopy and the final sample was later used for thermogravimetry and the XRPD analyses. Fig. 3 shows the IR spectra of 1,5-hexadiene adsorbed on $H S-M O R$ pre-outgassed at r.t. (curve a) and the subsequent evolution as a function of contact time (curves b,c). The spectrum of the 
molecule in the gas phase (curve a') is reported for comparison. The assignment of the signals of the molecule in this form, as well as the beginning of the contact with $H S-M O R$ and as a function of contact time is reported in Table 2. As a consequence of the interaction with the zeolite, the frequency of the modes producing signals in the accessible range is downshifted by a few

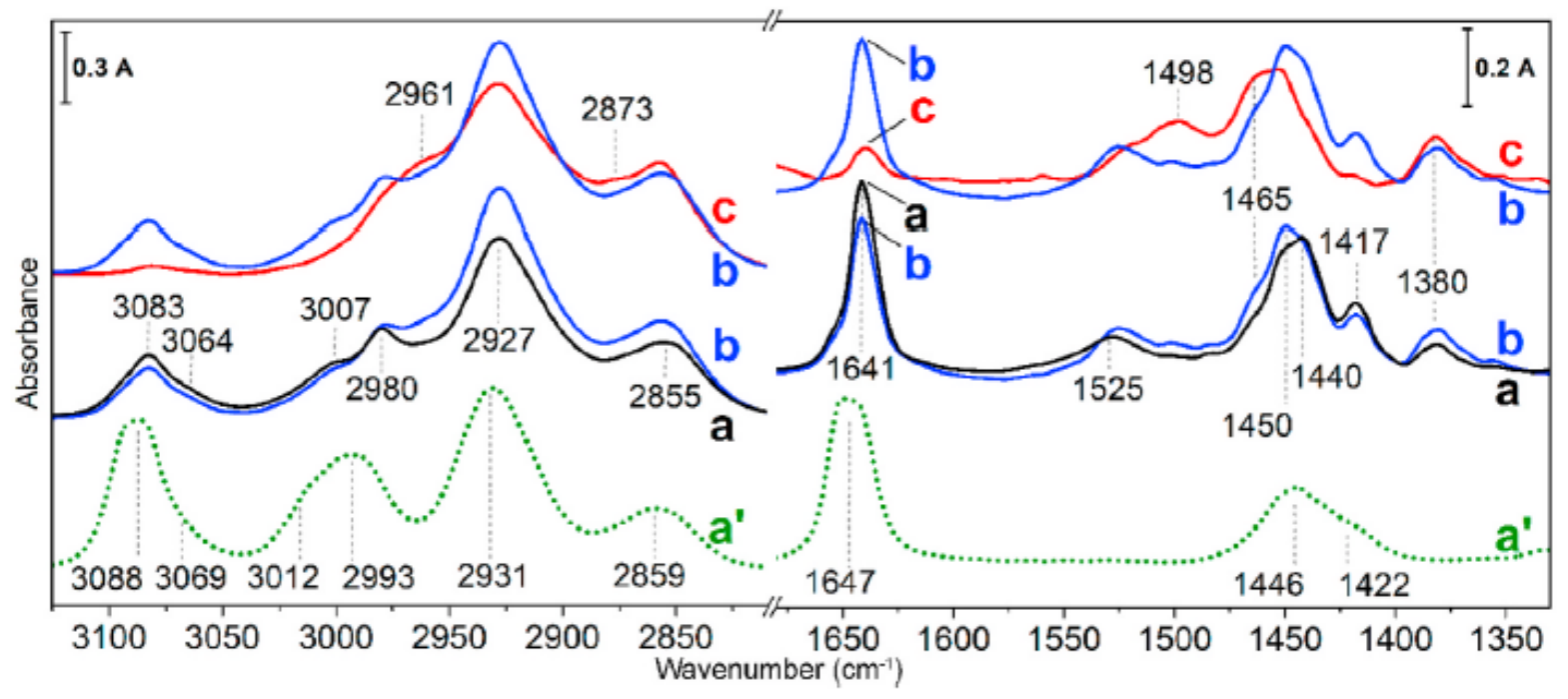

Fig. 3. IR spectra of 1,5-hexadiene: a') in vapor phase, at $\mathrm{p}=25 \mathrm{mbar}$; a) immediately after contact with $H S$ - $M O R$ (pre-outgassed at r.t. for $1 \mathrm{~h}$ ), at $\mathrm{p}=50$ mbar; b) after $1 \mathrm{~h}$ of contact; c) after 1 week of contact, and outgassing at r.t. for $1 \mathrm{~h}$. Spectra a-c are reported as resulting from the subtraction of the spectrum of $H S$-MOR prior 1,5-hexadiene adsorption. Spectrum b is shown in duplicate, for the sake of comparison with spectrum c.

wavenumbers, but the main distinctive aspect is constituted by the appearance of additional bands at 1525 and $1380 \mathrm{~cm}^{-1}$ and a shoulder at $1465 \mathrm{~cm}^{-1}$. These signals are assigned to the C-C stretching of allylic carbocation species, the symmetric deformation mode $(\delta \mathrm{sCH} 3)$ and the antisymmetric mode ( $\mathrm{Sas} \mathrm{CH} 3$ ) of - $\mathrm{CH} 3$ groups, respectively [66,67]. Corresponding $\mathrm{C}-\mathrm{H}$ stretching modes of the methyl groups are expected at higher frequency, where they should contribute as minor, unresolved components to the spectral pattern in the $3000-2800 \mathrm{~cm}^{-1} 1$ range due to stretching modes of $-\mathrm{CH} 2(\mathrm{sp} 2)$ and $-\mathrm{CH} 2(\mathrm{sp} 3)$. The presence of these additional signals indicates that a proton transfer occurred from the zeolite to adsorbed molecules. Indeed, the presence of Brønsted acid sites was assessed by IR spectroscopy of adsorbed ammonia (Fig. 2S, see Supporting Information). Moreover, the formation of allyl carbocation species can be explained in terms of an initial protonation of one of the terminal $\mathrm{C}=\mathrm{C}$ bonds, followed by a migration of the positive charge along the carbon atom chain towards the other terminal $\mathrm{C}=\mathrm{C}$, where the carbocations can experience resonance stabilization by delocalization of the positive charge to the adjacent $\pi$ bond ( $\mathrm{R}-\mathrm{C}(+) \mathrm{H}-\mathrm{CH}=\mathrm{CH} 2 \leftrightarrow \mathrm{R}-\mathrm{CH}=\mathrm{CH}-\mathrm{C}(+) \mathrm{H} 2)$. Such a reaction took place during the first hour of contact (curve $b$ ), as monitored by a decrease in intensity of the $v(\mathrm{C}=\mathrm{C})$ band $\left(1641 \mathrm{~cm}^{-1}\right)$ and of signals related to $-\mathrm{CH} 2(\mathrm{sp} 2)\left(3083,2980,1417 \mathrm{~cm}^{-1}\right)$ and $\mathrm{CH}(\mathrm{sp} 2)\left(3007 \mathrm{~cm}^{-1}\right)$. This was accompanied by an increase in the intensity of the band due to allylic carbocations (ca, $1525 \mathrm{~cm}^{-1}$ ) and - $\mathrm{CH} 3$ groups $\left(2961,2873,1465\right.$ and $1380 \mathrm{~cm}^{-1}$ ) (details on the assignment in Table 2). Despite pre-outgassing at r.t., water molecules unavoidably remained adsorbed on the inner walls of the IR cell and, over the following week, as the static condition was maintained, partial rehydration of the system occurred. The resulting $\mathrm{H} 2 \mathrm{O}$ 
Table 2

Assignment of 1,5-hexadiene infrared absorptions.

\begin{tabular}{|c|c|c|c|}
\hline \multirow[t]{2}{*}{ mode } & \multicolumn{3}{|c|}{ Frequency $\left(\mathrm{cm}^{-1}\right)$} \\
\hline & $\begin{array}{l}\text { gas phase }(\mathrm{p}= \\
10 \text { mbar })\end{array}$ & $\begin{array}{l}\text { HS-MOR hexa } \\
\text { (immediately after } \\
\text { adsorption) }\end{array}$ & $\begin{array}{l}\text { HS-MOR hexa (new } \\
\text { signals rising during } \\
\text { time evolution) }\end{array}$ \\
\hline$v_{s 2} \mathrm{CH}_{2}\left(\mathrm{sp}^{2}\right)$ & 3088 & 3083 & 3080 \\
\hline 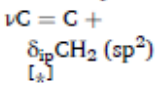 & 3069 & 3066 & \\
\hline$v \mathrm{CH}\left(\mathrm{sp}^{2}\right)$ & 3012 & 3007 & \\
\hline$\nu_{2} \mathrm{CH}_{2}\left(\mathrm{sp}^{2}\right)$ & 2993 & 2980 & \\
\hline$v_{a s} \mathrm{CH}_{3}$ & & & 2961 \\
\hline$v_{a 2} \mathrm{CH}_{2}\left(\mathrm{sp}^{3}\right)$ & 2931 & 2927 & \\
\hline$v_{2} \mathrm{CH}_{3}$ & & & 2873 \\
\hline$v_{2} \mathrm{CH}_{2}\left(\mathrm{sp}^{3}\right)$ & 2859 & 2855 & \\
\hline$\nu \mathrm{C}=\mathrm{C}$ & 1647 & 1641 & \\
\hline $\begin{array}{l}\text { VC-C allylic } \\
\text { carbocation }\end{array}$ & & 1525 & 1498 \\
\hline$\delta_{32} \mathrm{CH}_{3}$ & & & 1465 \\
\hline$\delta \mathrm{CH}_{2}\left(\mathrm{sp}^{3}\right)$ & $\begin{array}{l}\text { (unresolved) } \\
1446\end{array}$ & 1450 & \\
\hline $8 \mathrm{CH}_{2}\left(\mathrm{sp}^{3}\right)$ & $\begin{array}{l}\text { (unresolved) } \\
1446\end{array}$ & 1440 & \\
\hline$\delta_{i p} \mathrm{CH}_{2}\left(\mathrm{sp}^{2}\right)$ & 1422 & 1417 & \\
\hline$\delta_{2} \mathrm{CH}_{3}$ & & & 1380 \\
\hline
\end{tabular}

as: antisymmetric; s: symmetric; ip: in plane.

[*] From ref. [79]. The other assignments are from ref. [67]. stretching and bending modes interfered with the observation of the evolution of the $-\mathrm{CHx}$ (sp2 and sp3) and $\mathrm{C}=\mathrm{C}$ signals (Fig. $3 \mathrm{~S}$, see Supporting Information). When however, after one week of contact, the water molecules hydrating the system were removed by furthere outgassing at r.t., the whole spectral profile due to organic species became observable (curve c), revealing a strong decrease in intensity of the - $\mathrm{CH} 2(\mathrm{sp} 2)$ and $\mathrm{CH}$ (sp2) signals of the monomers in favor of those associated with the - $\mathrm{CH} 3$ groups. Moreover, it was possible to evaluate that the well resolved $v(\mathrm{C}=\mathrm{C})$ signal at $1641 \mathrm{~cm}^{-1}$ decreased in intensity of ca. $80 \%$ indicating that a large majority of

monomers were involved in the reaction. Indeed, it can be noted that an evolution of the band assigned to allylic carbocations also occurred: the signal initially at $1525 \mathrm{~cm}^{-1}$ is converted into a complex pattern at lower frequencies, constituted by at least three components, the most intense of them being located at $1498 \mathrm{~cm}^{-1}$. Such a behavior may be due to some change in the interaction with the zeolite lattice, in terms of interaction strength and of a possible heterogeneity of zeolite sites acting as anions.

3.2. Thermogravimetric analyses To gather a quantitative estimation of the guest species contained in the zeolite porosities, we performed thermal analyses on the sample after the reaction completion using as a reference the unloaded zeolite. Fig. 4 shows the thermal gravimetric analysis (TGA) and the corresponding differential thermogravimetry curve of $H S$ $M O R$ and of $H S-M O R$ hexa after one week of reaction (i.e. the sample corresponding to spectrum $\mathrm{c}$ in Fig. 3). When loaded in the TGA cell, both samples were exposed to air. Below $200{ }^{\circ} \mathrm{C}$, the unloaded $H S-M O R$ (curves a and a') shows a first weight loss (1.9 wt\%) in two distinguishable steps accounting for superficial water and water loosely adsorbed within the channels. A second weight loss of $2 \mathrm{wt} \%$ occurs in the $400-800{ }^{\circ} \mathrm{C}$ range, in good agreement with the silanol condensation process discussed by Fantini et al. [68]. The HS-MOR hexa (curves b and b') sample shows a reduced weight loss of $1.5 \mathrm{wt} \%$ below $200{ }^{\circ} \mathrm{C}$ which can be justified by a lesser quantity of water molecules within the zeolite channels, likely due to the presence of co-hosted hexa molecules. Confirmatory evidence of the decrease in water content of HS-MOR hexa was provided by XRPD data analysis (vide infra). The main weight loss of $7.5 \mathrm{wt} \%$ occurs in the $200-450{ }^{\circ} \mathrm{C}$ range, suggesting a unique process for the release of all the organic moieties. Above $450 \circ \mathrm{C}$, a further weight loss of $1.8 \mathrm{wt} \%$ due to the condensation of silanols is also observed for this sample. As a whole, considering the number of hydroxyls in the HS-MOR to be 


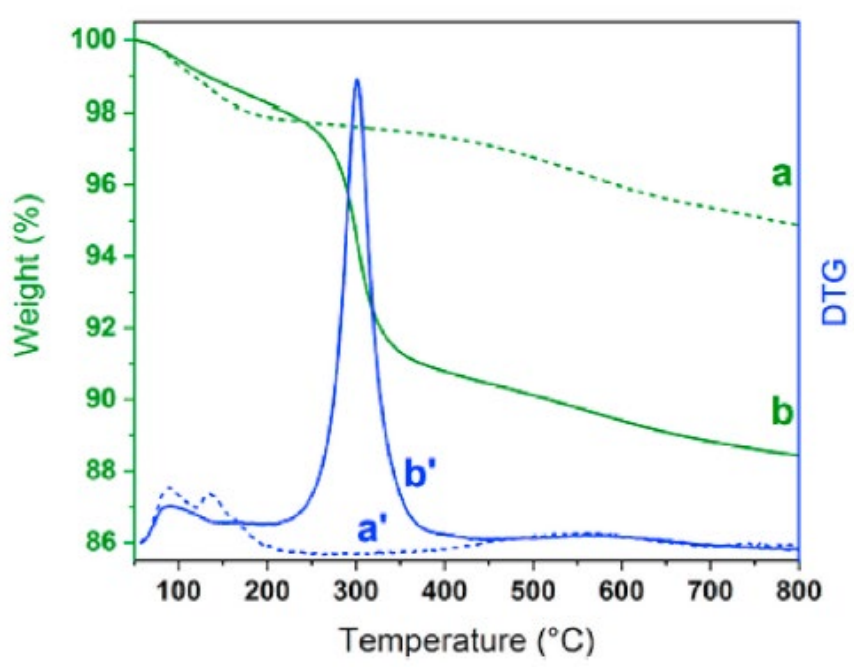

substantiated by the structural analysis below.
Fig. 4. TG (green) and DTG curves (blue) of $H S$ MOR (a, a') and HS-MOR hexa (b, b'). (For interpretation of the references to color in this figure legend, the reader is referred to the Web version of this article.)

constant before and after the hexa loading, the weight loss due to organic moieties corresponds to the presence of 17.4 carbon atoms (ca. 2.9 hexa molecules per unit cell, 1.5 hexa units per each $12 \mathrm{MR}$ ). Thus, the reaction evidenced by IR spectroscopy not only involved most of the 1,5-hexadiene molecules, but it also took place within the majority of the zeolite pores as is further

3.3. X-ray powder diffraction structural investigation From the XRPD patterns reported in Fig. 5 , it is possible to observe differences in the relative intensities of low angle reflections of $H S$ $M O R$ and $H S-M O R$ hexa samples.

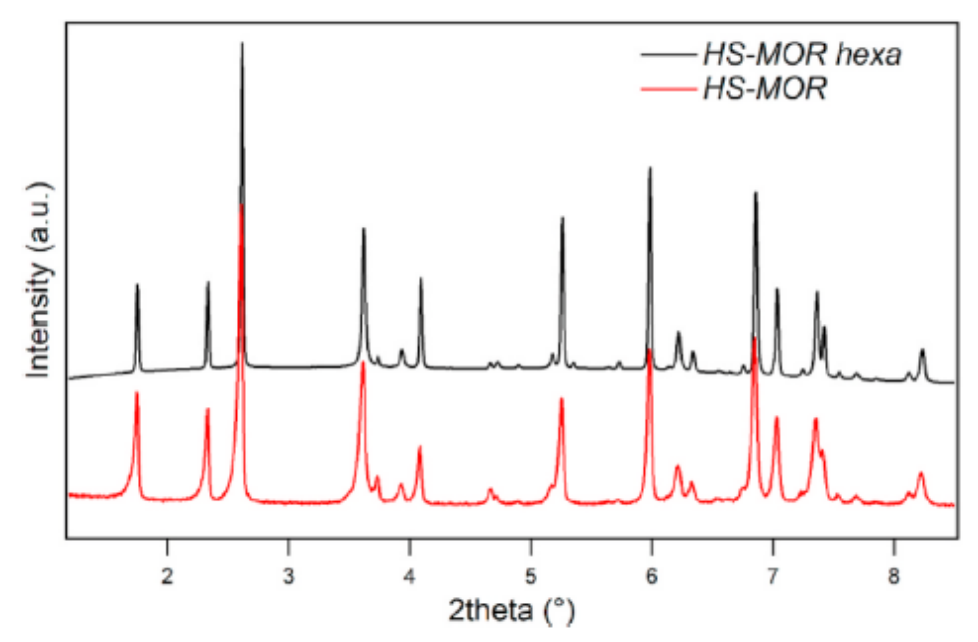

Fig. 5. Comparison of the XRPD patterns of $H S-M O R$ [40] and HS-MOR hexa. The two patterns have been rescaled and normalized for the same intensity on the third peak, at $2.6^{\circ}$. Selected 2 theta range is reported (full patterns are reported in Fig. $4 \mathrm{~S}$ in the Supporting Information).

This is a clear indication of the penetration of hexa molecules in the zeolite pores. Upon inspection of the Fourier map, it is possible to locate a chain composed of six carbon atoms running along [001] in the $12 \mathrm{MR}$ channel and lying on

the plane perpendicular to [100] (Fig. 6). The carbon atoms forming the chain occupy two fully occupied crystallographic positions $\mathrm{C} 1$ and $\mathrm{C} 2$ (with an average $\mathrm{C}-\mathrm{C}$ distance $\sim 1.5 \AA$ ) accounting for 2 and 4 carbon atoms in each channel of the unit cell, respectively. As a whole, based on the $\mathrm{C}$ sites multiplicity and on their full occupation, twelve $\mathrm{C}$ atoms are hosted in each unit cell (one chain of six carbon atoms per channel). The average distance of $\sim 1.5 \AA$ between $\mathrm{C}$ $\mathrm{C}$ atoms (see Table S2) indicates the formation of a continuous $\mathrm{C}$ atoms chain running along the 12 MR channel Fig. 6a). It is noteworthy that in a further Fourier difference map analysis, other residual peaks were found (Fig. $6 b$ and c). Some of them were very weak $(\rho=0.5)$ and near to $\mathrm{C} 1$ and $\mathrm{C} 2$ atoms, indicating that $\mathrm{C} 1$ and $\mathrm{C} 2$ atoms represent the average position of the chain. Other maxima were found at bond distance from the carbon atoms chain, in correspondence of the side pocket, suggesting the presence of some branches. Their low intensity $(\rho=0.6-0.7)$, and 
the fact that the tentative to insert them as carbon atom in the refinement failed leading to unreliable bond distances and thermal parameters, indicate that these branches are probably disordered. Anyway, the presence of the abovementioned residuals clearly suggests that the real
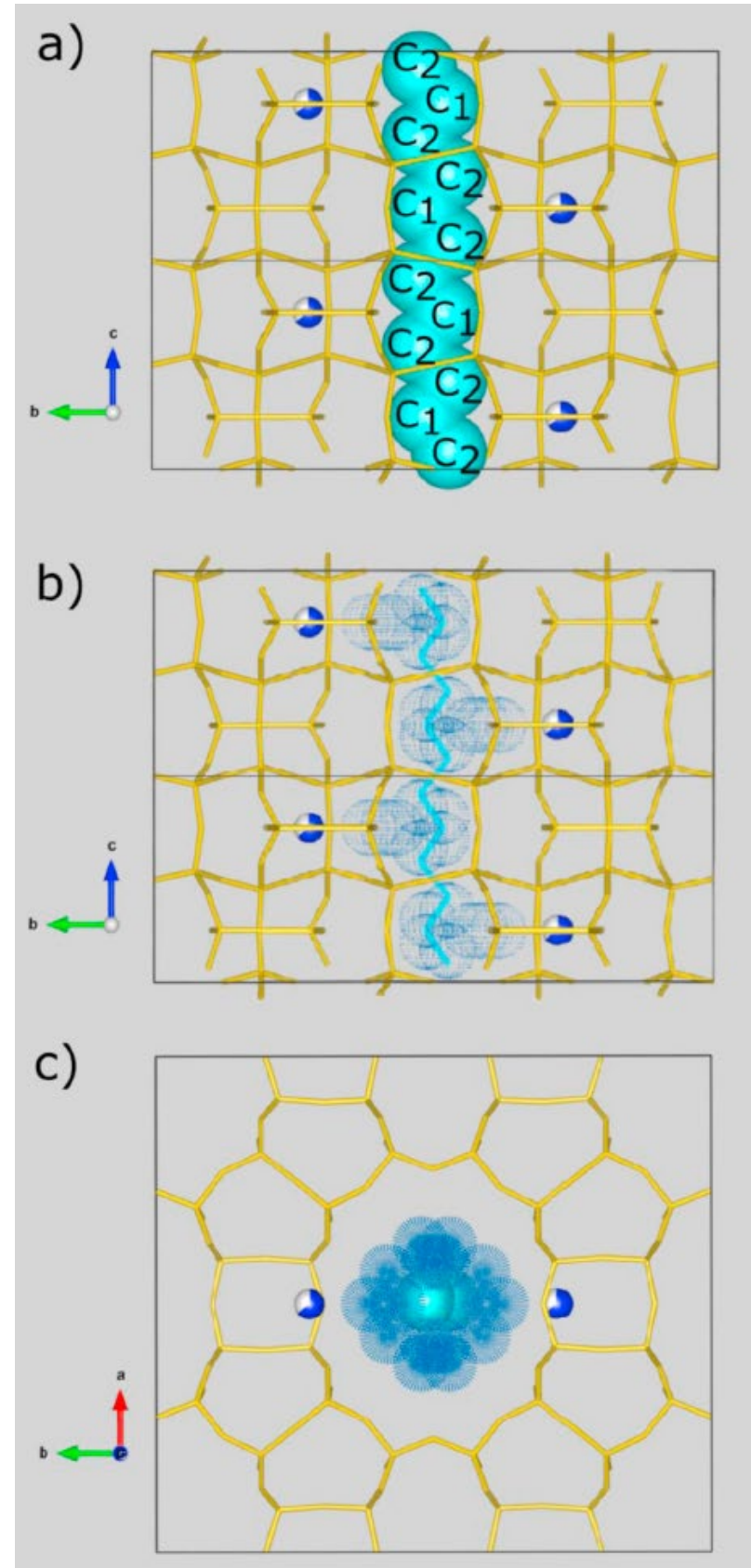

Fig. 6. Details of $H S-M O R$ hexa structure, data obtained by XRPD structural refinement. Two unit cells are shown along the $\mathrm{c}$ axis. Water molecules are represented in blue, while carbon atoms are in cyan. For clarity, just the extraframework content occupying the central channel is reported. a) $H S-M O R$ hexa structure reported along [100] direction; b) HS-MOR hexa structure reported along [100] direction showing the residual maxima (blue clouds) of the Fourier map positioned around the C1-C2 chain (in cyan); c) HS-MOR hexa structure reported along [001] direction showing the residual maxima (blue clouds) of the Fourier map positioned around the $\mathrm{C} 1-\mathrm{C} 2$ chain (in cyan). (For interpretation of the references to color in this figure legend, the reader is referred to the Web version of this article.)

polymer deviate from the simple zig-zag chain and that branchings of the molecules are present, consistently to what found by IR spectroscopy. The quantification of the molecules deriving from XRPD analyses is in good agreement with the TG results. In fact, the apparent discrepancy among the 17.4 carbon atoms (2.9 hexa units molecules from TG) and 12 carbon atoms (2 hexa units molecules form XRPD) can be explained by the presence of disordered branching of the polymer that can not be quantified by XRPD. An additional peak on the Fourier map, ascribed to a $\mathrm{H} 2 \mathrm{O}$ molecule site in the window between the $12 \mathrm{MR}$ and the side pocket, corresponds to the $\mathrm{W} 1$ site found in the pristine sample (see Table S2) [40]. The refinement of the occupancy factor leads to a total $\mathrm{H} 2 \mathrm{O}$ amount of 3.5 molecules per unit cell, in good agreement with the results of the thermal analysis (2.6 molecules per unit cell, $1.5 \mathrm{wt} \%)$. The water present in the channel is re-adsorbed once the sample is recovered in air after the hexa loading. The XRPD results indicate an extended polymerization reaction of the hexa molecules in the channels, in agreement with the IR results. After the hexa reaction, the cell parameters of the loaded sample show only a slight increase, mainly related to the lengthening of the $b$ parameter. In fact, the channels adapt to the new host: the $12 \mathrm{MR}$ channel becomes more circular and, as a consequence, the $8 \mathrm{MR}$ channel further lengthens along $a$ direction. The lengthening of 
the $b$ parameter is mainly due to the rotation of the $\mathrm{Si} 3$ and $\mathrm{Si} 4$ tetrahedra belonging to the $4 \mathrm{MR}$ ring (Table 3 and Fig. 7). This mechanism induces the lengthening of the O9-O10 distance, oriented along $b$ axis. Conversely, the $\mathrm{O} 10-\mathrm{O} 10$ diameter of the $12 \mathrm{MR}$ channel remains almost

Table 3

12 MR and 8 MR channel diameters and angles of HS-MOR [40] and HS-MOR hexa. The ellipticity parameters $\mathrm{E}$ is defined as the ratio between the largest and the smallest $\mathrm{O}-\mathrm{O}$ diameters, the Crystallographic Free Area (CFA) is also reported.

\begin{tabular}{lll}
\hline & HS-MOR $^{\mathrm{a}}$ & HS-MOR hexa \\
\hline $12 \mathrm{MR}$ & & \\
O7-O7 & 10.02 & $9.81(3)$ \\
O10-O10 & 8.85 & $8.86(5)$ \\
E & 1.13 & 1.11 \\
CFA $\left(\AA^{2}\right)$ & 35.1 & \\
8 MR & & \\
O7-O7 & 8.03 & $8.25(3)$ \\
O9-O9 & 5.58 & $5.52(4)$ \\
E & 1.44 & 1.5 \\
CFA $\left(\AA^{2}\right)$ & 10.61 & \\
4 MR & & \\
O9-O10 & 4.01 & $4.06(3)$ \\
O4-O4 & 3.35 & $3.33(3)$ \\
O4-O10-O4 & 77.32 & $77.029(2)$ \\
O9-04-O10 & 100.28 & $100.808(2)$ \\
\hline
\end{tabular}

a From Ref. [40].

b This work.

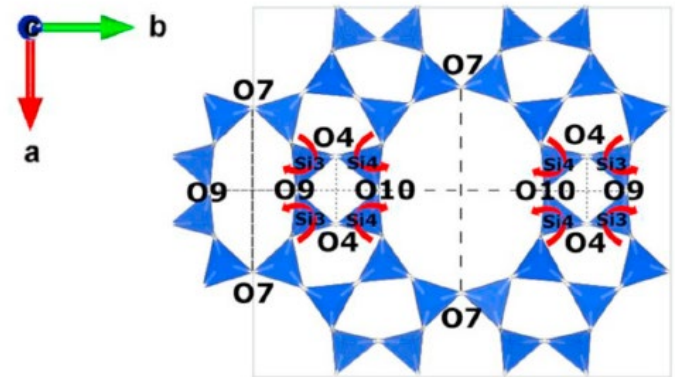

Fig. 7. Mechanism of cell adapting due to the polymer formation: the $12 \mathrm{MR}$ channel becomes more circular and, as a consequence, the $8 \mathrm{MR}$ channel further lengthens along $a$ direction.

unchanged due to the steric hindrance of the organic chain lying on the $b c$ plane. The polymer chain weakly interacts with

the framework oxygen O10, as suggested by the C2-O10 distance of about $3.6 \AA$ (Table 3S, Supporting Information).

3.4. Modeling of 1,5-hexadiene reacted in HS-MOR Fig. 8 depicts the optimized structures of the five 1,5-hexadiene derived polymers considered in our study. All models are compatible with $H S-M O R$ and stabilized by the framework. The $H S-M O R /$ polymer binding energies are -29.65 , $-41.64,-43.60,-40.07,-38.80 \mathrm{kcal}$ mol-1 per simulation cell (p.s.c.) for Models A, B, C, D, E, respectively. The order of the binding energies can be understood by considering that the dominant host-guest interactions are of the van der-Waals type. Model A - the polymer without side moieties (poly (methylene)), resulting from a head-tail reaction for all molecules - has the smallest binding energy. The framework stabilizing effect is lowest for Model A due to the large separation from the zeolite walls (minimum C-Oframework distance $=3.85 \AA$ ). In contrast, the minimum $\mathrm{C}$-Oframework distances are much shorter for the other models $(3.18 \AA, 3.31 \AA, 3,24$ $\AA$, and $3.28 \AA$ for Models B, C, D, E, respectively) and in line with other organic species in zeolite channels [18,51,69-76]. Hence, Model A is the least probable structure among the five models. This hypothesis is in agreement with the IR data, which evidenced terminal methyl groups. Model B - with side propyl groups hosted in the HS-MOR side pockets - has a binding energy p.s.c. about $12 \mathrm{kcal}$ mol $\square^{-1}$ greater than Model A. Model B has the shortest minimum COframe distance (3.18 $\AA$ ), due to the partial penetration of the propyl in the MOR side pockets (Fig. 8b). Model C has a 1-D chain of cyclopentane units, known as poly (methylene-1,3 cyclopentane), which derives from Ziegler-Natta catalysts [77]. Model $\mathrm{C}$ has the greatest binding energy because of the optimal host-guest contacts. The cyclopentane chain perfectly fits into the $12 \mathrm{MR}$ thereby maximizing the favorable van-der-Waals interactions with the host without distortion of the framework. The IR evidence of terminal methyl groups suggests that Model C should be less likely than a branched polymer. Hence Model D - having both branching groups 
and cyclopentane units - might be a realistic model of the polymer chain inside MOR: its binding energy is comparable to Models B and C and the ethyl group fits well in the host. Model E has a branching vinyl group and it is energetically very close to Model D. Since IR analyses

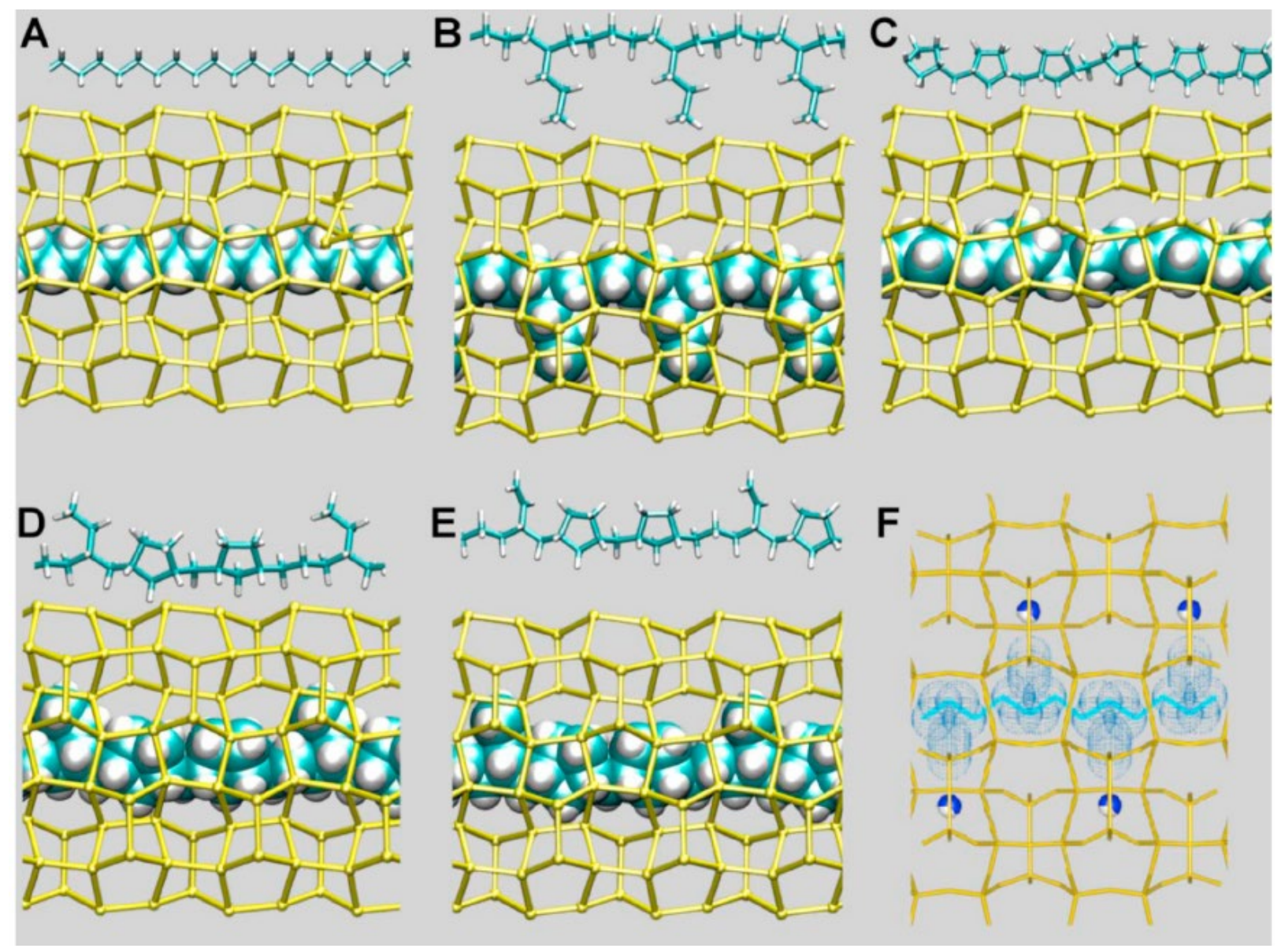

Fig. 8. A-E): Graphical representation of the optimized structures of $H S-M O R$ encapsulating: Model A) linear, nonbranched alkyl polymer chain; Model B) chain with side propyl groups penetrating in the MOR side pockets; Model C) all-cyclopentane-chain featuring a PMCP polymer; Model D) chain containing two cyclopentane units and one branching ethyl group p.s.c.; Model E) chain containing two cyclopentane units and one branching vinyl group p.s.c. The five 1,5-hexadiene based polymer chains inside the HS-MOR framework are highlighted in van-der-Waals representation. For each model composite, the correspondent polymer chain is also shown on top of the composite in stick representation. All the five polymer chains are stabilized by the $H S-M O R$ framework. Color codes: $H S-M O R$ framework = yellow; $\mathrm{C}=$ cyan; $\mathrm{H}=$ white. $\mathrm{F}$ ): $H S-M O R$ hexa structure showing the residual maxima of the Fourier map positioned around the $\mathrm{C} 1-\mathrm{C} 2$ chain (color codes as in Fig. $7 \mathrm{~b}$ ). All structures are projected in the bc plane. (For interpretation of the references to color in this figure legend, the reader is referred to the Web version of this article.)

indicate that the almost complete loss of the double $\mathrm{C}=\mathrm{C}$ bonds signals occurs over a very long time (about a week), Model E might be a possible model for the polymer, which still contains unreacted double bonds. To establish which model better compares with the XRPD data, we applied to the calculated atomic positions of our models the symmetry operations of the $\mathrm{Cmcm}$ group and superposed them to the refined structure. As known, the refined structure of the composite results from averaging over different configurations with symmetry lower than the ideal zeolite framework [3]. Indeed, Fig. 9a-e clearly show that the computed framework positions are symmetrically distributed around the lines denoting the refined structure. In line 
with other zeolite frameworks $[15,53,55]$, the "averaging effect" is more evident for the $\mathrm{O}$ positions due to the flexibility of the Si-O-Si angles. The comparison highlights the good agreement between the calculated and refined framework structures. Fig. 9 reveals that the two models containing both cyclopentyl units and side moieties (Models D, E) best match the experimental results. The linear $\mathrm{C}-\mathrm{C}$ chain of Model A exhibits the worst comparison with the residual maxima of the Fourier map, because of its low steric encumbrance. In fact, although the co-presence of some portion of non-branched zig-zag polymer chain inside the channel is not excluded by the structural data, this configuration is the least chemically plausible among the considered models in view of the larger amount of $\mathrm{H}$ atoms that would be needed to saturate the olefinic bonds (formally, one $\mathrm{H}_{2}$ molecule per each hexadiene molecule) with respect to that required by an intramolecular cyclization process (only one $\mathrm{H}_{2}$ per each polymer chain). Moreover, as indicated by the energetics of the models, such a linear zig-zag chain is strongly energetically unfavored with respect to the other models, because it could not be stabilized effectively by van-der-Waals interactions with the channel walls. Model B has two symmetrized carbon positions - corresponding to the terminal methyl group of the propyl chain - located in the window between $12 \mathrm{MR}$ and side pocket. Therefore, these locations (ascribed to a $\mathrm{H} 2 \mathrm{O}$ site (W1) in the XRPD refinement) might also be due to terminal methyl groups. However, also Model B, with respect to the cyclopentyl-chains in Models C, D, E, would require a higher number of (formal) $\mathrm{H}_{2}$ molecules to saturate the double bond (one per hexadiene molecule vs. one per polymer chain). Hence, the most probable structure of the confined polymer should be a 1D-chain with both cyclopentane units and side moities. Polymers containing vinyltetramethylene (VTM) units from 1, 5-hexadiene were obtained with homogeneous ZieglerNatta catalysts $[77,78]$. Considering the time scale of the full process as deduced by IR measurements (one week), model E - with vinyl side groups between cyclic units - may be a possible first polymerization product.

4. Conclusions In this work, we prepared a hybrid material in which 1,5-hexadiene was polymerized to form an almost linear chain and protected inside a high silica mordenite acting as mold and scaffold. The combination of IR, TGA and diffraction data indicated that: i) the zeolite pores were filled with 1,5-hexadiene; ii) all hexa monomers that entered in the zeolite channels reacted; iii) chains of covalently bonded $\mathrm{C}$ atoms run along the main channels of $H S-M O R$. Combining this evidence with insights from modeling, we propose the formation of polymers as long as the zeolite channels constituted by cyclopentane units and side moieties. We showed that, in the hydrophobic nanochannels at ambient conditions, the hexa guest molecules undergo a slow transformation to a continuous chain, consisting of cyclic units intercalated by short side chains, that nicely fits in the host channels. Despite the formation of olefinic side groups along the main chain during the process, cross linking is prevented by the confining environment of the zeolite channel, which forces a linear growth of the polymer. Due to the presence of a few acid sites distributed along the channel walls, once the molecules are properly organized inside the voidspace architecture, they are prone to react yielding quasi unidimensional polymers, whose structure is shaped by the geometrical features of the zeolite mold. 
Funding sources This work was carried out in the framework of the PRIN project ZAPPING (PRIN2015 Prot.2015HK93L7) funded by the Italian MIUR. FAR2018 Uninsubria is acknowledged for funding.

CRediT authorship contribution statement Marco Fabbiani: Investigation, Conceptualization, Data curation, Writing - original draft. Giorgia Confalonieri: Investigation, Data curation, Writing - original draft. Sara Morandi: Methodology, Formal analysis. Rossella Arletti: Project administration, Supervision, Funding acquisition. Simona Quartieri: Project administration, Writing - review \& editing. Mario Santoro: Visualization, Conceptualization. Francesco Di Renzo: Conceptualization, Visualization. Julien Haines: Conceptualization, Validation. Riccardo Fantini: Investigation. Gloria Tabacchi: Methodology, Formal analysis, Writing - original draft. Ettore Fois: Methodology, Resources, Writing - review \& editing. Giovanna Vezzalini: Project administration, Resources, Writing - review \& editing. Gabriele Ricchiardi: Conceptualization, Resources. Gianmario Martra: Project administration, Resources, Supervision.

Declaration of competing interest The authors declare that they have no known competing financial interests or personal relationships that could have appeared to influence the work reported in this paper.

Acknowledgment This paper is dedicated to our friend and colleague Gianmario Martra prematurely passed away during the paper revision process. M. Fabbiani is gratefully indebted to C. Nannuzzi for the support in the in situ experiments and data elaborations. Authors thank the staff of ID15b and ID22, ESRF, for the help in X-ray diffraction data collection. Ms. C. Merrett is acknowledged for the English language revision.

Appendix A. Supplementary data Samples parameters, structural refinement parameters, infrared spectra during time evolution and full XRPD patterns. The CIF file of the XRPD data is also provided. Supplementary data to this article can be found online at https://doi.

org/10.1016/j.micromeso.2020.110728.

\section{References}

[1] J. `Cejka, A. Corma, S. Zones, Zeolites and Catalysis: Synthesis, Reactions and Applications, 2, WILEY-VCH Verlag GmbH \& Co. KGaA, Weinheim, Germany, 2010.

[2] R.K.S. Almeida, J. Per'ez-Pariente, L. G'omez-Hortigüela, Microporous Mesoporous Mater. 300 (2020) 110149.

[3] G. Tabacchi, ChemPhysChem 19 (2018) 1249-1297.

[4] G. Calzaferri, S. Huber, H. Maas, C. Minkowski, Angew. Chem. Int. Ed. 42 (2003) 3732-3758.

[5] S. Quartieri, A. Sani, G. Vezzalini, E. Galli, et al., Microporous Mesoporous Mater. 30 (1999) $77-87$.

[6] E. Fois, G. Tabacchi, S. Quartieri, G. Vezzalini, J. Chem. Phys. 111 (1999) 355-359.

[7] E. Fois, A. Gamba, C. Medici, G. Tabacchi, S. Quartieri, E. Mazzucato, R. Arletti, G. Vezzalini, V. Dmitriev,

Microporous Mesoporous Mater. 115 (2008) 267-280.

[8] G. Calzaferri, in: Struct. Bond., Springer, Berlin, Heidelberg, 2020, pp. 1-73, https://doi.org/10.1007/430_2020_57.

[9] C.S. de Matos, M.M. N’obrega, M.L.A. Temperini, V.R.L. Constantino, Appl. Clay Sci. 174 (2019) $152-158$.

[10] M. Chołuj, W. Bartkowiak, Int. J. Quant. Chem. 119 (2019).

[11] G. Tabacchi, E. Fois, G. Calzaferri, Angew. Chem. Int. Ed. 54 (2015) 11112-11116.

[12] L. Giussani, G. Tabacchi, S. Coluccia, E. Fois, Int. J. Mol. Sci. 20 (2019) 2965.

[13] Q. Ke, T. Sun, X. Wei, Y. Guo, S. Xu, S. Wang, Chem. Eng. J. 359 (2019) 344-353. 
[14] X. Zhou, T.A. Wesolowski, G. Tabacchi, E. Fois, G. Calzaferri, A. Devaux, Phys. Chem. Chem. Phys. 15 (2013) 159-167.

[15] R. Arletti, E. Fois, L. Gigli, G. Vezzalini, S. Quartieri, G. Tabacchi, Angew. Chem. Int. Ed. 56 (2017) 21052109.

16] P. Woodtli, S. Giger, P. Müller, L. S“'agesser, N. Zucchetto, M.J. Reber, A. Ecker, D. Brühwiler, Dyes Pigments 149 (2018) 456-461.

[17] P. Cao, O. Khorev, A. Devaux, L. S“agesser, A. Kunzmann, A. Ecker, R. H“aner, D. Brühwiler, G. Calzaferri, P. Belser, Chem. - A Eur. J. 22 (2016) 4046-4060.

[18] L. Gigli, R. Arletti, G. Tabacchi, M. Fabbiani, J.G. Vitillo, G. Martra, A. Devaux, I. Miletto, S. Quartieri, G. Calzaferri, E. Fois, J. Phys. Chem. C 122 (2018) 3401-3418.

[19] T. Bein, P. Enzel, Angew Chem. Int. Ed. Engl. 28 (1989) 1692-1694.

[20] G.F. McCann, G.J. Millar, G.A. Bowmaker, R.P. Cooney, J. Chem. Soc. Faraday. Trans. 91 (1995) 43214328.

[21] E. Fois, A. Gamba, G. Tabacchi, J. Phys. Chem. B 102 (1998) 3974-3979.

[22] R. Grau-Crespo, A.G. Peralta, A.R. Ruiz-Salvador, A. G'omez, R. L'opez-Cordero, Phys. Chem. Chem. Phys. 2 (2000) 5716-5722.

[23] C.O. Arean, M.R. Delgado, P. Nachtigall, H.V. Thang, M. Rube`s, R. Bul'anek, P. Chlubn'a-Eli'a`sov'a, Phys. Chem. Chem. Phys. 16 (2014) 10129-10141.

[24] M. Fischer, Chem. - A Eur. J. 25 (2019) 13579-13590.

[25] G. Li, E.A. Pidko, ChemCatChem 11 (2019) 134-156.

[26] C. Pereira, G.T. Kokotailo, R.J. Gorte, J. Phys. Chem. 95 (1991) 705-709.

[27] G.D. Gatta, P. Lotti, G. Tabacchi, Phys. Chem. Miner. 45 (2018) 115-138.

[28] M. Santoro, F.A. Gorelli, R. Bini, J. Haines, A. van der Lee, Nat. Commun. 4 (2013) 1557.

[29] D. Scelta, M. Ceppatelli, M. Santoro, R. Bini, F.A. Gorelli, A. Perucchi, M. Mezouar, A. Van Der Lee, J. Haines, Chem. Mater. 26 (2014) 2249-2255.

[30] M. Santoro, K. Dziubek, D. Scelta, M. Ceppatelli, F.A. Gorelli, R. Bini, J.M. Thibaud, F. Di Renzo, O. Cambon, J. Rouquette, P. Hermet, A. Van Der Lee, J. Haines, Chem. Mater. 27 (2015) 6486-6489.

[31] G. Confalonieri, M. Fabbiani, R. Arletti, S. Quartieri, F. Di Renzo, J. Haines, G. Tabacchi, E. Fois, G. Vezzalini, G. Martra, M. Santoro, Microporous Mesoporous Mater. 300 (2020) 110163.

[32] J.L. Mackey, Z. Yang, K.N. Houk, Chem. Phys. Lett. 683 (2017) 253-257.

[33] D. Walther, T. D"ohler, K. Heubach, O. Klobes, B. Schweder, H. G"orls, Zeitschrift Fur Anorg. Und Allg. Chemie 625 (1999) 923-932.

[34] H.M. Jeong, J.H. Song, K.W. Chi, I. Kim, K.T. Kim, Polym. Int. 51 (2002) 275.

[35] W.M. Meier, Zeitschrift Fur Krist. - New Cryst. Struct. 115 (1961) 439-450.

[36] C. Baerlocher, L.B. McCusker, D.H. Olson, Atlas of Zeolite Framework Types, Published on behalf of the Structure Commission of the International Zeolite Association by Elsevier, 2007.

[37] R. Arletti, A. Martucci, A. Alberti, L. Pasti, M. Nassi, R. Bagatin, J. Solid State Chem. 194 (2012) 135-142.

[38] A. Martucci, L. Pasti, M. Nassi, A. Alberti, R. Arletti, R. Bagatin, R. Vignola, R. Sticca, Microporous Mesoporous Mater. 151 (2012) 358-367.

[39] S. Blasioli, A. Martucci, G. Paul, L. Gigli, M. Cossi, C.T. Johnston, L. Marchese, I. Braschi, J. Colloid Interface Sci. 419 (2014) 148-159.

[40] R. Arletti, L. Leardini, G. Vezzalini, S. Quartieri, L. Gigli, M. Santoro, J. Haines, J. Rouquette, L. Konczewicz, Phys. Chem. Chem. Phys. 17 (2015) 24262-24274.

[41] C. Prescher, V.B. Prakapenka, High Pres. Res. 35 (2015) 223-230.

[42] A.C. Larson, R.B. Von Dreele, LAUR (1994) 86-748.

[43] B.H. Toby, J. Appl. Crystallogr. 34 (2001) 210-213.

[44] P. Thompson, D.E. Cox, J.B. Hastings, J. Appl. Crystallogr. 20 (1987) 79-83.

[45] E.S. Fois, J.I. Penman, P.A. Madden, J. Chem. Phys. 98 (1993) 6352-6360.

[46] J. Klime`s, D.P. Tew, J. Chem. Phys. 151 (2019) 234108.

[47] M. Fischer, F.O. Evers, F. Formalik, A. Olejniczak, Theor. Chem. Acc. 135 (2016) 257.

[48] M. Fischer, Z. für Kristallogr. - Cryst. Mater. 230 (2015) 325-336.

[49] F. Trudu, G. Tabacchi, A. Gamba, E. Fois, J. Phys. Chem. A 111 (2007) 11626. 
[50] M. Abatal, A.R. Ruiz-Salvador, N.C. Hern'andez, Microporous Mesoporous Mater. 294 (2020) 109885.

[51] E. Fois, G. Tabacchi, G. Calzaferri, J. Phys. Chem. C 114 (2010) 10572-10579.

[52] L. Gigli, R. Arletti, E. Fois, G. Tabacchi, S. Quartieri, V. Dmitriev, G. Vezzalini, Crystals 8 (2018) 79.

[53] F. Trudu, G. Tabacchi, E. Fois, Am. Mineral. 104 (2019) 1546-1555.

[54] R. Arletti, E. Fois, G. Tabacchi, S. Quartieri, G. Vezzalini, Adv. Sci. Lett. 23 (2017) 5966-5969.

[55] G. Confalonieri, S. Quartieri, G. Vezzalini, et al., Microporous Mesoporous Mater. 284 (2019) 161-169.

[56] C. Ceriani, E. Fois, A. Gamba, et al., Am. Mineral. 89 (2004) 102-109.

[57] E. Fois, A. Gamba, G. Tabacchi, S. Coluccia, G. Martra, J. Phys. Chem. B 107 (2003) 10767-10772.

[58] E. Fois, G. Tabacchi, D. Barreca, A. Gasparotto, E. Tondello, Angew. Chem. Int. Ed. 49 (2010) 1944-1948.

[59] C. Betti, E. Fois, E. Mazzucato, C. Medici, S. Quartieri, et al., Microporous Mesoporous Mater. 103 (2007)

190-209.

[60] G. Tabacchi, E. Gianotti, E. Fois, G. Martra, L. Marchese, S. Coluccia, A. Gamba, J. Phys. Chem. C 111 (2007) 4946-4955.

[61] D. Barreca, E. Fois, A. Gasparotto, R. Seraglia, et al., Chem. - A Eur. J. 17 (2011) 10864-10870.

[62] G. Tabacchi, M. Fabbiani, L. Mino, G. Martra, E. Fois, Angew. Chem. Int. Ed. 58 (2019) 12431-12434.

[63] C. Deiana, E. Fois, G. Martra, S. Narbey, F. Pellegrino, G. Tabacchi, ChemPhysChem 17 (2016) 1956-1960.

[64] J. Groppi, L. Casimiro, M. Canton, S. Corra, M. Jafari-Nasab, et al., Angew. Chem. Int. Ed. (2020), https://doi.org/10.1002/anie.202003064.

[65] C. Deiana, G. Tabacchi, V. Maurino, S. Coluccia, G. Martra, E. Fois, Phys. Chem. Chem. Phys. 15 (2013) 13391-13399.

[66] C. Paz’e, B. Sazak, A. Zecchina, J. Dwyer, J. Phys. Chem. B 103 (1999) 9978-9986.

[67] N.B. Colthup, L.H. Daly, S.E. Wiberly, Introduction to Infrared and Raman Spectroscopy, Academic Press, New York, 1975.

[68] R. Fantini, R. Arletti, S. Quartieri, M. Fabbiani, S. Morandi, G. Martra, F. Di Renzo, G. Vezzalini, Microporous Mesoporous Mater. 294 (2020) 109892.

[69] L. Gigli, R. Arletti, G. Tabacchi, E. Fois, J.G. Vitillo, G. Martra, G. Agostini, S. Quartieri, G. Vezzalini, J. Phys. Chem. C 118 (2014) 15732-15743.

[70] G. Tabacchi, G. Calzaferri, E. Fois, Chem. Commun. 52 (2016) 11195-11198.

[71] E. Fois, G. Tabacchi, G. Calzaferri, J. Phys. Chem. C 116 (2012) 16784-16799.

[72] W. Insuwan, K. Rangsriwatananon, J. Meeprasert, S. Namuangruk, Y. Surakhot, N. Kungwan, S.

Jungsuttiwong, Microporous Mesoporous Mater. 241 (2017) 372-382.

[73] H. Manzano, L. Gartzia-Rivero, J. Ba nuelos, I. L'opez-Arbeloa, J. Phys. Chem. C 117 (2013) 13331-13336.

[74] M. Fischer, J. Phys. Chem. C 124 (2020) 5690-5701.

[75] V. Martínez-Martínez, R. García, L. G'omez-Hortigüela, J. P'erez-Pariente, I. L'opez- Arbeloa, Chem. - A Eur. J. 19 (2013) 9859-9865.

[76] E. Fois, et al., Langmuir 29 (2013) 9188-9198.

[77] P.D. Hustad, G.W. Coates, J. Am. Chem. Soc. 124 (2002) 11578-11579.

[78] R.T. Mathers, G.W. Coates, Chem. Commun. 10 (2004) 422-423.

[79] G. Herzberg, Molecular Spectra and Molecular Structure. II. Infrared and Raman Spectra of Polyatomic Molecules, Tenth, Van Nostrand Company, Princeton, New Jersey, US, 1962. 